\title{
PRÁtiCAS de EDUCAÇÃo LITERÁRIA E de PROMOÇÃO DA LITERATURA
}

\author{
Fernando Azevedo ${ }^{2}$ \\ Ângela Balça ${ }^{3}$
}

\begin{abstract}
Resumo: Neste artigo apresentam-se e descrevem-se exemplos de práticas que fomentam a educação literária e que promovem a literatura em contextos que se configuram como contextos de leitura não formais. Estas práticas foram levadas a cabo por estudantes universitários, da Licenciatura em Educação Básica. Este artigo tem como objetivos dilucidar o conceito de educação literária bem como apresentar e descrever um conjunto de práticas de promoção da literatura em distintos contextos de leitura não formais. No final do artigo, apresenta-se um balanço destas práticas, do qual se destaca uma boa adesão das instituições envolvidas, não sendo possível, todavia, pela natureza do trabalho desenvolvido, uma avaliação do impacto real das mesmas na consolidação de comunidades leitoras.
\end{abstract}

Palavras-chave: Educação literária; Promoção da literatura; Práticas; Contextos de leitura não formais

\section{Practices of literary education and promotion of literature}

\begin{abstract}
In this article we present and describe some examples of practices that promote literary education and that promote literature in contexts that are configured as non-formal reading contexts. These practices were carried out by university students of the Degree in Basic Education. This article aims to elucidate the concept of literary education as well as present and describe a set of literature promotion practices in different non - formal reading contexts. At the end of the article, we present a balance of these practices, which highlights a good adhesion of the institutions involved, but it is not possible, however, by the nature of the work developed, an evaluation of their real impact in the consolidation of reading communities.
\end{abstract}

Keywords: Literary education; Literature promotion; Practices; Non-formal reading contexts

\footnotetext{
${ }^{1}$ Este texto foi financiado por Fundos Nacionais através da FCT (Fundação para a Ciência e a Tecnologia) e cofinanciado pelo Fundo Europeu de Desenvolvimento Regional (FEDER) através do COMPETE 2020 Programa Operacional Competitividade e Internacionalização (POCI) no âmbito do CIEC (Centro de Investigação em Estudos da Criança da Universidade do Minho) com a referência POCI-(01-0145-FEDER007562

${ }^{2}$ Universidade do Minho. (fernando.uminho@gmail.com)

${ }^{3}$ Universidade de Évora. (apb@uevora.pt)
}

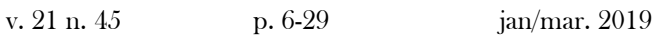




\section{INTRODUÇÃO}

Este artigo debruçará a sua atenção sobre um conjunto de práticas de promoção da educação literária e da literatura fora de contextos tradicionalmente associados a ela: a escola e os processos de educação formal. Se a promoção da leitura literária está tradicionalmente ligada à instituição escolar, muitos têm sido os sinais da sociedade, ultimamente, no sentido de se configurarem espaços não formais de fomento da leitura e da leitura literária. A presença de espaços de leitura em cafés, hotéis, hospitais e/ou centros de saúde, juntas de freguesia, entre outros, exigem em simultâneo a formação de sólidos e competentes mediadores de leitura.

O presente artigo apresentará e descreverá práticas de promoção da literatura desenvolvidas por alunos universitários voluntários portugueses, finalistas do curso de Licenciatura em Educação Básica. Estes alunos, na faixa dos 20 anos de idade, possuem um conhecimento geral sobre estudos literários, um breve conhecimento sobre literatura infanto-juvenil e práticas de mediação literária, concretizado na frequência de três unidades curriculares semestrais. As práticas de promoção da literatura apresentadas inserem-se na unidade curricular de Literacia e Mediação Leitora.

Os objetivos subjacentes à implementação destas práticas de promoção da literatura são promover a leitura e a literatura; tornar conhecidos diferenciados autores e livros; fomentar o contacto com espaços/equipamentos como sendo espaços de leitura não formais; estimular a leitura e a literatura no ambiente das ferramentas digitais.

Metodologicamente, com a implementação destas práticas, os estudantes são mobilizados a utilizar processos investigativos no âmbito da investigaçãoação que permitem a aquisição de competências no espaço do desenvolvimento profissional ao longo da vida. Os alunos desenvolvem um trabalho de campo, fazem um trabalho de prospeção (recolhem dados dos contextos de intervenção através de instrumentos e técnicas diferenciadas como observação participante, produção de notas de campo, entrevistas, documentos institucionais e bibliográficos, entre outros), para poderem analisar e compreender os contextos onde implementarão a sua intervenção prática.

É de notar que este curso de graduação confere aos alunos a possibilidade de ingresso no mercado de trabalho ou o prosseguimento de estudos para uma 
pós-graduação profissionalizante, que lhes permitirá serem educadores de infância e/ou professores do 1. ciclo do Ensino Básico e/ou professores do 2..${ }^{\circ}$ ciclo do Ensino Básico. Estimular os alunos finalistas a serem agentes ativos na promoção da leitura e da literatura explica-se não só pelo facto de eles experimentarem práticas relevantes para o seu desenvolvimento profissional futuro, como também pelo facto de aprenderem o como fazer e, tendo oportunidade, o poderem reiterar noutros contextos considerados significativos. Caso estes alunos não prossigam os seus estudos pós-graduados, eles serão técnicos de educação que poderão trabalhar em distintos contextos educativos não formais: bibliotecas, ateliers de tempos livres, museus, associações sociais, culturais ou desportivas, autarquias, entre outros. As ferramentas ganhas no âmbito da educação literária e da promoção da literatura serão preciosas, para o desenvolvimento de um trabalho sério em redor do livro e da leitura literária junto de públicos tão distintos.

Deste modo, para além desta introdução, este artigo aborda o conceito de educação literária e dá conta de um conjunto de práticas de promoção da literatura em diversos contextos de leitura não formal. Por fim, apresenta-se o balanço das atividades, as conclusões e as referências bibliográficas.

\section{EDUCAÇÃO LITERÁRIA}

Conhecer textos e autores literários faculta ao sujeito um conhecimento do mundo importante para que ele possa estabelecer conexões e relações intertextuais, inferindo muito daquilo que se entrediz ou que não se explicita abertamente. De facto, conhecer temas, estilemas, figuras de estilo, fragmentos literários, convenções estéticas, símbolos, expressões hipercodificadas, autores, etc, permite que o sujeito se sinta membro de uma casa comum e possa, com desenvoltura e segurança, completar muito daquilo que o texto não diz, mas promete ou implica. É o domínio mais ou menos alargado da educação literária (CERRILLO E SENÍS, 2005; MENDOZA, 1999) que possibilita ao leitor preencher os espaços em branco do texto, na célebre formulação expressa por Umberto Eco (1983).

A literatura, concretizando uma imaginação criadora, ajuda o leitor a interrogar o mundo, a pensá-lo de modo alternativo, liberto das constrições do mundo empírico e histórico-factual. De facto, não mantendo uma relação de 
fidelidade especular com o mundo empírico e histórico-factual, os mundos possíveis da literatura permitem questionar indiretamente o leitor e suscitam nele a consecução de importantes efeitos cognitivos. Como exemplarmente expressa Ofélia Paiva Monteiro (2016, s/p),

\begin{abstract}
A Literatura vive de um mergulhar nos interiores, desconstrói o construído, retira a força da afirmação convencida que procura ser convincente... A Literatura desarticula muito. A Literatura brota do nosso mundo interior (...). Se a Literatura vier dos nossos fundos é uma literatura de interrogações sempre, de interrogações existenciais cuja resposta não é simples. O que se pensa da morte? De onde se vem? Para onde se vai? Todas estas questões fundamentais fazem viver a Literatura. E estas questões incomodam, desarticulam, retiram a confiança. A Literatura é um elemento perturbador. (MONTEIRO, 2016, s/p)
\end{abstract}

O texto literário é construído a partir de uma interação sígnica complexa que promove deliberadamente a polifuncionalidade e a pluri-isotopia dos significados. $\mathrm{O}$ conjunto dos seus códigos que compõem estes textos configuram, como realçou Aguiar e Silva (2007) -, um autêntico policódigo literário, que inclui, entre outros, o código linguístico, o código técnicocompositivo, o código semântico-pragmático ou o código ideológico. Assim a leitura do texto literário é necessariamente plural e requer, da parte do leitor, uma aprendizagem (a educação literária) e uma capacidade para ler numa multiplicidade de planos: a leitura na superfície do texto mas também as leituras latentes e não explícitas.

Assim, como sublinhou Azevedo (2018, p. 5),

Formar leitores literários constitui hoje um desafio e uma necessidade. Um desafio porque, sendo uma atividade voluntária, que se alcança pela recriação de espaços e momentos de prazer e fruição, não existe propriamente uma estratégia que possa ser considerada como única e eficaz para a obter. Uma necessidade porque o domínio da leitura literária permite desenvolver cognitivamente o sujeito e, articulando-se com a capacidade de ler o mundo de modo não ingénuo, possui virtualidades fundamentais na capacidade de exercício da cidadania. (AZEVEDO, 2018, p. 5) 
Ser um sujeito educado literariamente e, nesse sentido, apto a ler, na sua pluralidade de sentidos, qualquer texto e, em particular, os textos literários, é um objetivo a fomentar coletivamente. A escola é, naturalmente, o espaço privilegiado para a formação de leitores literários. Mas importa ter em conta que este desiderato só é plenamente alcançável se existir um compromisso coletivo com ele. Formar leitores literários resultará tanto melhor quanto existir um enquadramento geral e coletivo nesse sentido.

Além disso a leitura, quando entendida como projeto pessoal e afetivo, permite a instrução, a educação e a diversão do indivíduo. Como refere Lourdes Mata (2008), a leitura de histórias é uma atividade importante, na medida em que promove o desenvolvimento da linguagem, o desenvolvimento de mecanismos de seleção da informação e sua compreensão, assim como conhecimentos sobre a linguagem escrita e atitudes positivas face à leitura e às atividades a ela ligadas. Todavia a leitura de histórias possibilita, acima de tudo, a emoção e a afinidade entre o leitor e o texto, potenciadora de uma relação afetiva duradora do leitor com a leitura de literatura.

A pesquisa tem demonstrado a mais-valia da interação precoce de crianças e jovens com textos literários, seja em contextos formais de aprendizagem seja em contextos não formais (BOSMA \& GUTH, 1995; SORENSEN \& LEHMAN, 1995; BAKER \& WIGFIELD, 1999; CERRILLO; LARRAÑAGA E YUBERO, 2002; POSLANIEC, 2004; AZEVEDO, 2006; CERRILLO, 2007; RIBEIRO E VIANA, 2009; BALÇA E PIRES, 2013; BARROS, 2014; AZEVEDO E BALÇA, 2016).

\section{PRÁTICAS DE PROMOÇÃO DA EDUCAÇÃO LITERÁRIA E DA LITERATURA: EXEMPLOS MAIS RELEVANTES}

A promoção da educação literária e da literatura em contextos de leitura não formais tem feito um caminho longo no tempo, mas ainda muito há a construir para a sua consolidação. Desde a primeira década do século XXI que o Plano Nacional de Leitura, em Portugal, tem proposto um olhar e múltiplas ações sobre a leitura e a leitura de literatura em contextos de leitura não formais. Paralelemente, distintos investigadores têm estado atentos a estas questões da leitura nestes contextos e da formação de mediadores de leitura 
(CERRILLO, 2006，2010; AZEVEDO，2007; BALÇA，2014; BALÇA, AZEVEDO E BARROS, 2017; BARROS, 2018).

Porém, debrucemo-nos sobre o papel do Plano Nacional de Leitura na sua chamada de atenção para a leitura, também de literatura, fora da instituição escolar. Na primeira fase do Plano Nacional de Leitura (2006-2016), uma das preocupações subjacentes, entre os seus objetivos, era a criação de um ambiente social favorável à leitura e o enriquecimento das competências dos atores sociais, desenvolvendo a ação de professores e de mediadores de leitura, formais e informais. De igual modo, nas suas linhas de estratégia, o Plano Nacional de Leitura propunha a criação de oportunidades de leitura e contacto com os livros em espaços não convencionais de leitura e a disponibilização de orientação e apoio direto e on-line a práticas promotoras de leitura na família, na biblioteca pública e noutros contextos culturais. Os contextos não formais de leitura encontravam-se bem identificados pelo Plano Nacional de Leitura, ao prever diversas áreas de intervenção, tais como: instituições culturais - teatros, museus; instituições de solidariedade social; hospitais, centros de saúde; prisões; transportes públicos.

O Plano Nacional de Leitura entrou na sua segunda fase (2017-2027), com o grande desiderato de

Pensar a educação e a cultura como eixos de governação
pressupõe a assunção da leitura como prioridade política,
tomando esta competência como básica para o acesso plural ao
conhecimento e ao enriquecimento cultural - indispensáveis ao
exercício de uma cidadania ativa e ao desenvolvimento
económico e social do país. Neste âmbito, o domínio alargado da
competência da leitura é perspetivado como condição
fundamental para a construção e consolidação de uma sociedade
livre, com coesão social, acesso democrático à informação, ao
conhecimento, e à criação e fruição culturais. (PNL, 2018)

Muitas são as Ações, os Programas, os Projetos previstos para os próximos 10 anos do Plano Nacional de Leitura, sob a égide de vários objetivos, dos quais destacamos "Consciencializar a sociedade do valor e da importância da leitura; Estimular uma cultura e um ambiente económico-social favoráveis à multiplicação das práticas e dos contextos sociais de leitura.” (PNL, 2018). Estes objetivos, já presentes na primeira fase do Plano Nacional de Leitura, voltam a alertar para a continuidade de um trabalho em redor da leitura em intrínseca ligação com a sociedade e com os seus distintos contextos. 
Se nos debruçarmos sobre as Ações, presentes na página web do Plano Nacional de Leitura, encontramos uma multiplicidade delas, porém, no âmbito deste artigo, queremos realçar a Ação "Território Leitor. Promover a Leitura". Esta Ação é promovida por distintos mediadores de leitura e, dentro dela, há atividades que se centram em contextos de leitura não formais, isto é, fora da instituição escolar. A título de exemplo, referiremos algumas que, de certo modo, também inspiraram as práticas dos estudantes universitários, relatadas neste artigo.

Andreia Brites dinamiza a atividade Livros a quem os lê que consiste na criação de um portal virtual de alojamento de sugestões de livros, neste caso, para adolescentes. Entre outras coisas, propõe-se que cada entrada corresponda a um título de um livro. Nesta entrada no portal virtual constará a temática do livro, uma reflexão crítica sobre o mesmo e a sua associação a eventuais leitores. Cristina Taquelim é a responsável pela atividade Transumâncias Leitoras. Com esta atividade visa-se o desenvolvimento de uma oficina de leitura e escrita, onde se cruzam o performativo, o diálogo, a leitura em voz alta em redor da oratura e da literatura. Ler Juntos é a atividade promovida por Paula Cusati e consiste na dinamização de encontros de pais e filhos em redor da leitura e da discussão de livros, apostando-se também na formação da família como mediadora de leitura.

Por conseguinte, a aposta na formação de mediadores de leitura e nos contextos de leitura não formais continua na agenda do Plano Nacional de Leitura (2017-2027). E este grande projeto nacional, amplamente conhecido e apoiado pela sociedade portuguesa, omnipresente na instituição escolar, também se constitui como um respaldo para o trabalho com os estudantes universitários, no âmbito das Licenciaturas e dos Mestrados profissionalizantes que habilitam para a docência. Deste modo, como mencionámos anteriormente, quer as práticas quer os contextos de leitura não formais, escolhidos pelos estudantes universitários, no âmbito de distintas disciplinas, projetos, trabalhos de investigação académica refletem o espírito do Plano Nacional de Leitura.

Assim de entre as numerosas práticas de promoção da educação literária e da literatura, que apresentaremos de seguida, planeadas e executadas pelos estudantes da Licenciatura em Educação Básica, selecionámos aquelas que nos pareceram mais pertinentes, quer pela sua originalidade quer pelo seu eventual impacto junto de públicos leitores diversificados. 
A todas estas práticas, de um modo geral, subjazem distintos objetivos: promover a leitura e a literatura; tornar conhecidos diferenciados autores e livros; fomentar o contacto com espaços/equipamentos como sendo espaços de leitura não formais; estimular a leitura e a literatura no ambiente das ferramentas digitais.

Estas práticas inseriram-se na unidade curricular de Literacia e Mediação Leitora e, metodologicamente, os alunos contataram com processos investigativos no âmbito da investigação-ação, tais como o trabalho de campo. As práticas foram planificadas e executadas sob a supervisão de professores/investigadores da área, após contacto, observação participante e entrevistas, consoante necessário, com diversas instituições municipais e nacionais. As notas de campo produzidas pelos alunos bem como a leitura de documentos bibliográficos e/ou institucionais foram fulcrais para o desenho das práticas implementadas.

Por se tratar de práticas promovidas em contextos não formais, algumas dependentes dos indivíduos que passavam naquela hora naquele espaço, não foi feito o registo do número de participantes nas atividades nem desenhado o seu perfil socioeconómico. Deixamos também claro que essa não era a principal preocupação no implementar destas atividades. A principal e real preocupação na implementação destas atividades era que os estudantes experienciassem processos investigativos no âmbito da investigação-ação, como o trabalho de campo, neste caso em contextos não formais, onde maioritariamente não é possível determinar, à partida, qual será o público-alvo do trabalho a desenvolver. Nestas situações, os alunos, na sua vida profissional futura, terão de ser capazes de desenhar e implementar práticas e/ou projetos de mediação/promoção da literatura para públicos e mesmo para locais inesperados.

As práticas que aqui se apresentam e descrevem foram implementadas durante um semestre, do ano letivo 2016/2017, em distintos contextos não formais, da cidade de Braga, Portugal.

Em seguida, procederemos à apresentação, descrição e posterior balanço destas práticas de promoção da educação literária e da literatura.

1 - Clube de leitura - realizado numa base mensal, presencial, e com temáticas suficientemente abertas e atraentes, de modo a assegurar a inclusão de 
todos. As várias sessões do clube de leitura foram realizadas em espaços culturais da cidade de Braga, como livrarias e bibliotecas, tendo tido como participantes os alunos finalistas da Licenciatura em Educação Básica. Depois de uma breve explicação acerca do modelo organizacional do clube e da sua metodologia (AZEVEDO E MARTINS, 2011; MCMAHON E RAPHAEL, 1997; RAPHAEL; PARDO E HIGHFIELD, 2002), os leitores foram informados dos temas de cada sessão e foi realizada a calendarização das atividades. A primeira sessão foi consagrada aos livros da minha vida, tendo cada leitor sido estimulado a partilhar a obra considerada emblemática ou referencial para si, independentemente de valorações de qualidade ou outras, enfatizando as razões que o levavam a atribuir relevo aquela obra. O objetivo subjacente era criar uma comunidade de leitores, capazes de se reunirem, com frequência, e de partilharem leituras. Progressivamente, as temáticas foram-se alargando e incluíram, entre outras, por exemplo, escritores de âmbito lusófono, vencedores de Prémio Nobel da Literatura, escrita de receção leitora infantojuvenil, etc.

A experiência do clube de leitura presencial complementou a visita e a exploração de outros clubes de leitura online, como, por exemplo, plataformas como o GoodReads.com (https://www.goodreads.com/), o ManyBooks.net (http://manybooks.net//), o 24 Symbols (https://www.24symbols.com/) ou o Bookcrossing (http://www.bookcrossing.com/).

2 - Histórias \& Companhia - configura um jogo para crianças dos 8-10 anos, pensado para ativar a memória literária e aceder ao conhecimento de histórias novas. O jogo (figura 1), similar ao conhecido "Jogo da Glória", consiste na utilização de diversos cartões-pergunta distribuídos em cinco categorias: mímica, desenho, imitar sons, descobrir palavras através de pistas e perguntas. A ideia é que os participantes possam, de forma lúdica, explorar histórias novas e outras já conhecidas, como é o caso das histórias tradicionais infantis. A atividade foi desenvolvida num centro de atividades para tempos livres (ATL) da cidade de Braga e teve como dinamizadores um grupo de alunos finalistas da Licenciatura em Educação Básica e como participantes crianças que frequentavam esse espaço. 


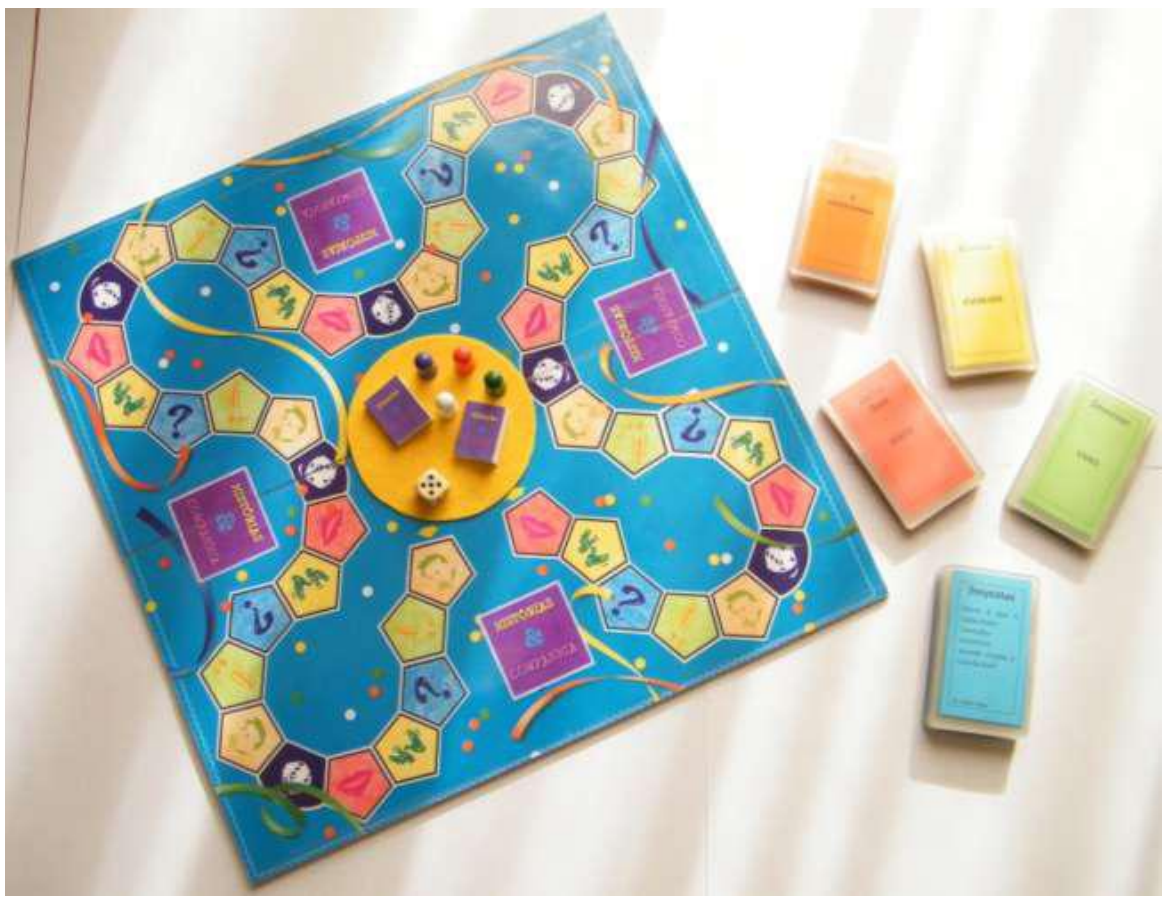

Figura 1 - Jogo inventado Histórias \& Companhia

3 - Terminal do Livro - constitui uma outra atividade de motivação para a leitura, desenvolvida na Estação de Caminhos de Ferro da cidade de Braga. O seu público-alvo eram os adultos. Atendendo a que o tempo disponível para a atividade não era muito extenso (os utentes da estação de comboios da cidade dispõem de pouco tempo para estar no cais de embarque, antes de entrar no mesmo), esta consistiu em propor, aos potenciais leitores, a leitura de um pequeno extrato de uma obra literária, pedindo um desfecho criativo para a mesma. O desfecho foi produzido oralmente e gravado pelos promotores da atividade.

4 - Pede um café, Inspira-te! - A atividade, desenvolvida em vários cafés da cidade de Braga (Pastelaria Montalegrense, Pastelaria Florbela, Café Pão de 
Forma e Café 33), durante cerca de três semanas, foi realizada com o objetivo de despertar a curiosidade dos potenciais usuários para a leitura literária. A atividade consistiu em associar, a cada café pedido, uma breve citação literária estimuladora, acompanhada da indicação da sua fonte (figuras 2 e 3). Em complemento, nos cafés, que colaboraram na atividade desenvolvida pelos alunos, foi facultado um espaço físico (uma mesa ou algumas prateleiras), aonde se colocaram exemplares das obras de onde foram retiradas as citações estimuladoras, por forma a suscitar o interesse pela leitura (figura 4). A adesão foi considerada muito positiva, tendo os responsáveis pelos estabelecimentos comerciais solicitado a continuação da atividade até ao final do ano escolar.

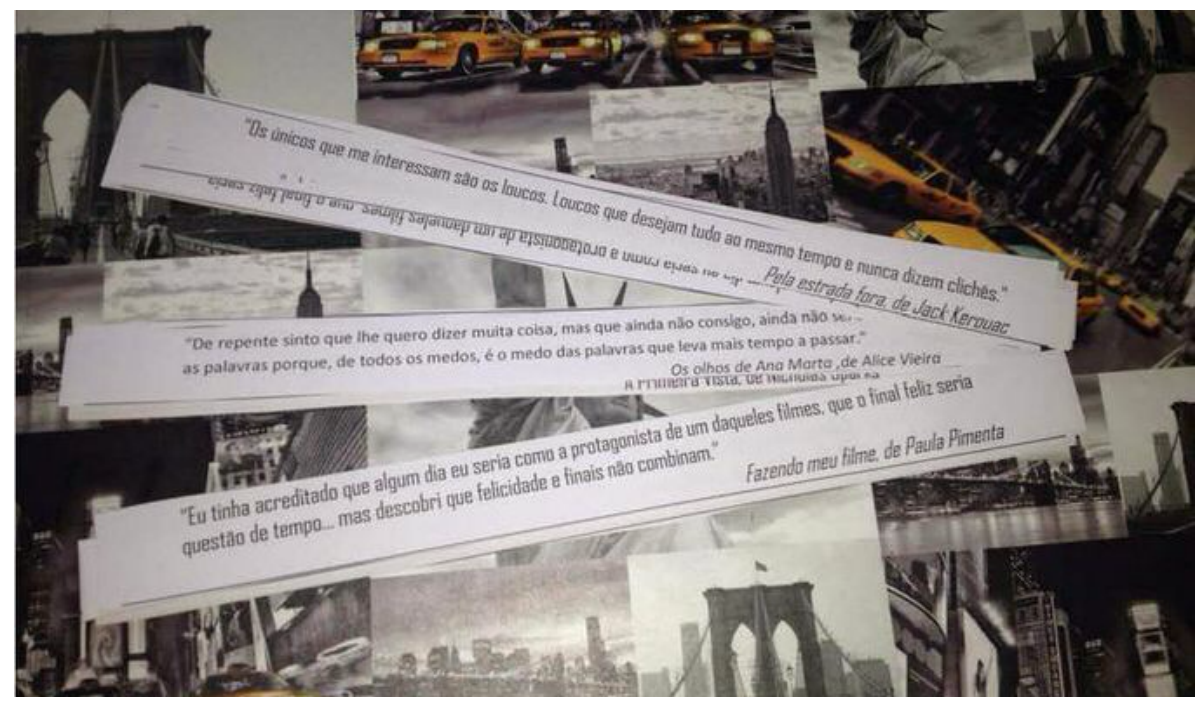

Figura 2 - A preparação das citações literárias que vão acompanhar o café na atividade 4 Pede um café, Inspira-te! 
Figuras 3 - As citações literárias que acompanhavam o café na atividade 4 - Pede um café, Inspira-te!

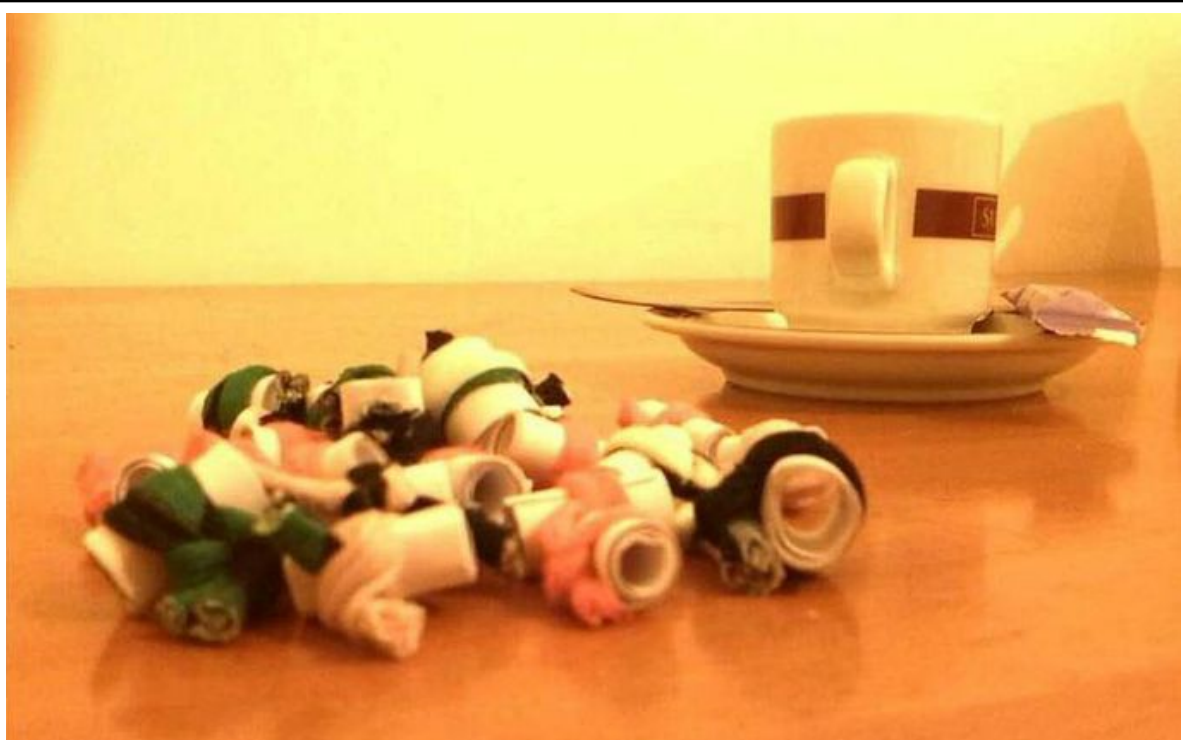




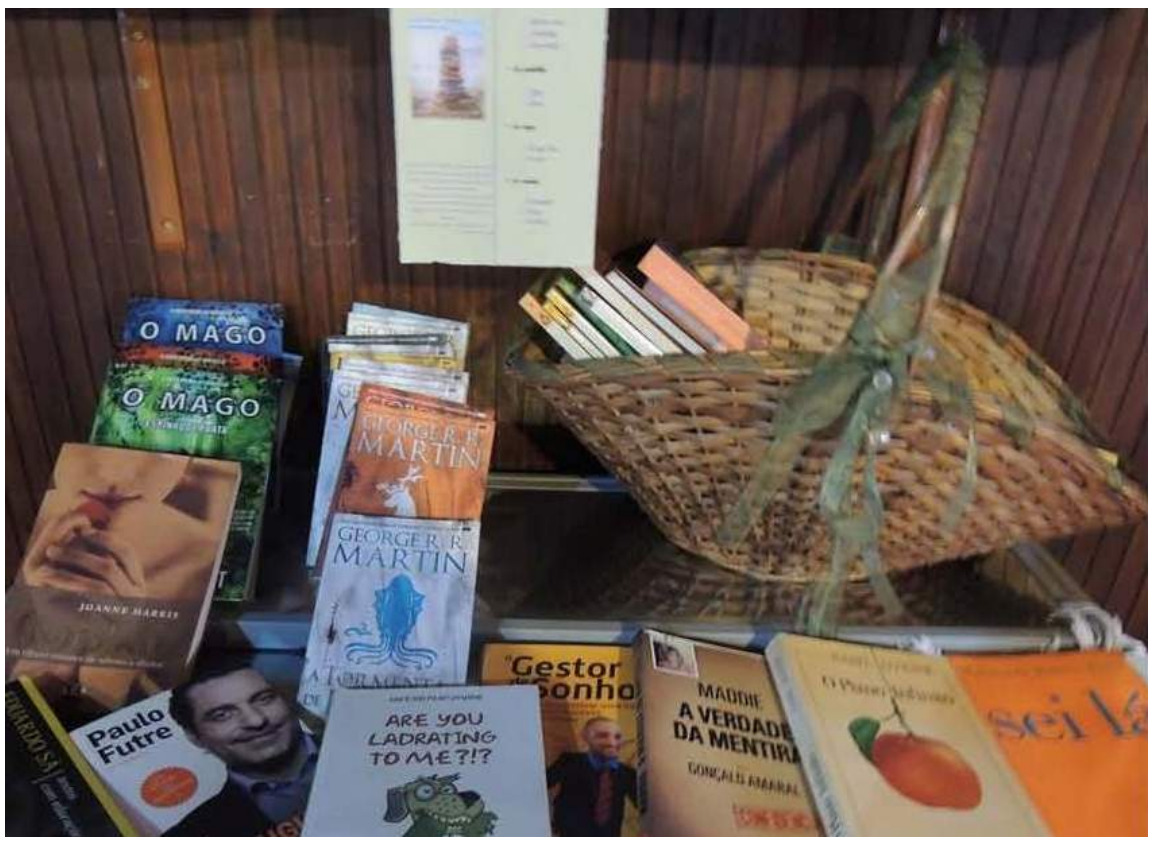

Figura 4 - Pormenor da mesa com livros acessíveis para leitura no café.

5 - De Garfo e Livro! - é uma atividade similar à anterior, que foi realizada, durante duas semanas, num conhecido restaurante da cidade de Braga. Para além de atividades de animação leitora, os clientes, antes de iniciarem a refeição ou após a terem terminado, tinham a possibilidade de contactar com algumas obras, lendo extractos das mesmas, motivados por citações literárias estimuladoras, que acompanhavam ora a entrega da ementa ora a chegada do café ou da sobremesa. O restaurante, identificado com uma tarja do projeto (figura 5), tinha, no seu interior, uma estante com livros (figura 6), livremente acessíveis pelos seus frequentadores. 

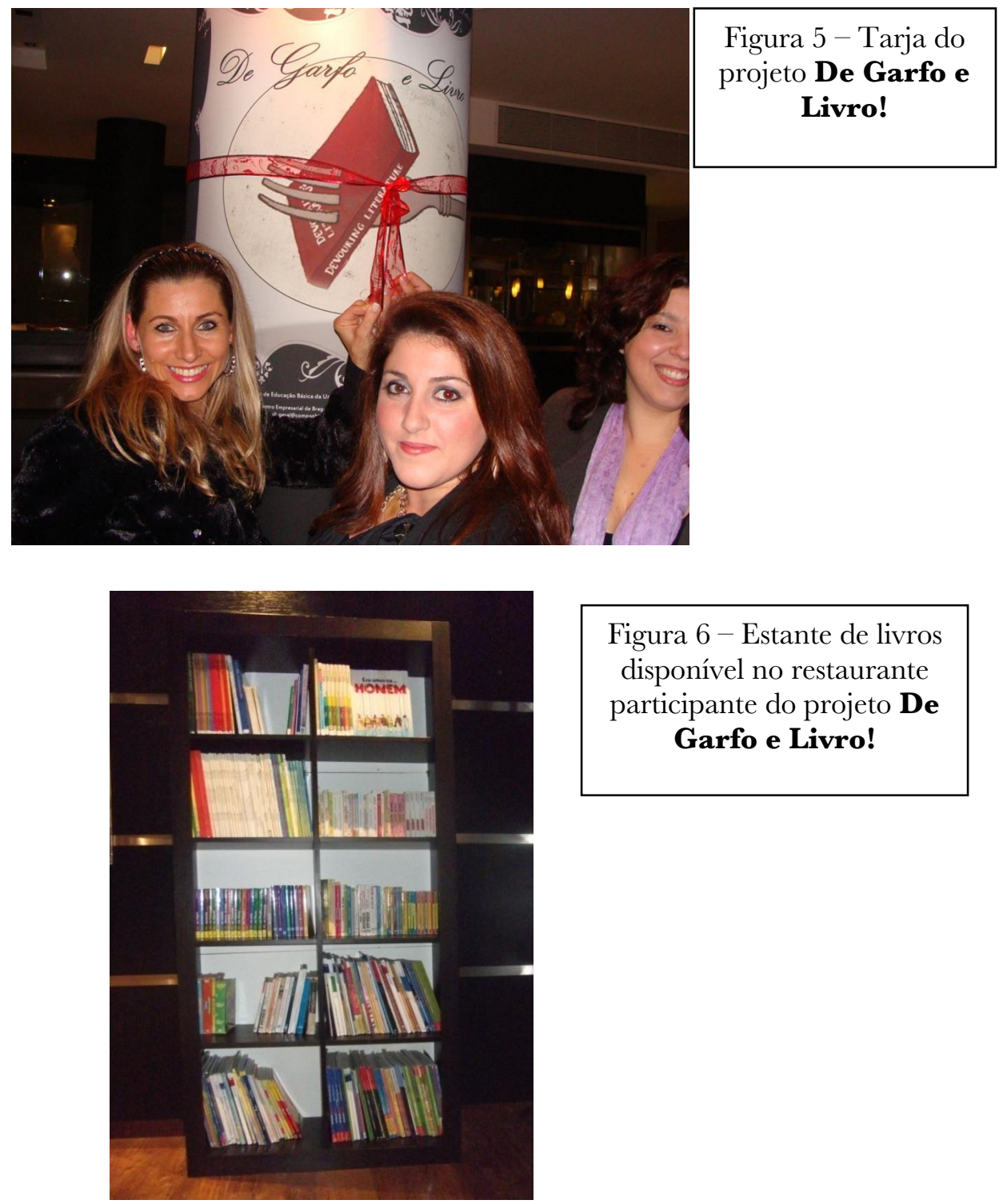

Figura 6 - Estante de livros disponível no restaurante participante do projeto $\mathbf{D e}$ Garfo e Livro!

6 - Ar puro respirar, a ler vai-te ajudar - constitui uma atividade de dinamização da leitura, desenvolvida ao ar livre, num parque infantil da cidade de Braga. O parque escolhido situa-se no centro da cidade (Parque Infantil 25 de Abril) e, à sua volta, existe o jardim de infância São Lázaro e três escolas EB1 São Lázaro, EB2,3 André Soares e Escola Secundária D. Maria II - 
permitindo, aos voluntários da iniciativa, um contacto direto com crianças/jovens de várias idades (entre os 3 e os 18 anos) e com quem os acompanha. É de salientar que este parque, além de diversos materiais de diversão, apresenta uma grande área revestida por árvores, que proporciona uma agradável interação homem-meio ambiente.

7 - Espaços de interação na web - Atendendo a que a internet é, cada vez mais, um espaço que os leitores visitam assiduamente e no qual navegam várias horas ao dia, um grupo de alunos, inspirado nos princípios da partilha de leituras da plataforma Bookcrossing, decidiu criar um blog, onde foram disponibilizadas breves resenhas de livros, jogos, quizzes. Este blog foi posteriormente complementado por uma conta de Instagram, onde o recurso à imagem possibilitou dar a conhecer locais emblemáticos da leitura e da cultura da cidade de Braga (bibliotecas, livrarias, fóruns culturais, feiras do livro, clubes de leitura, etc.), bem como capas de obras entendidas como relevantes para os seus potenciais leitores. Iniciativa similar, embora com outro alcance e outra capacidade de interação, foi igualmente a abertura de contas dedicadas à promoção da leitura e da literatura em redes sociais, como o Facebook (figuras 7 e 8), YouTube, Hi5 e outras.

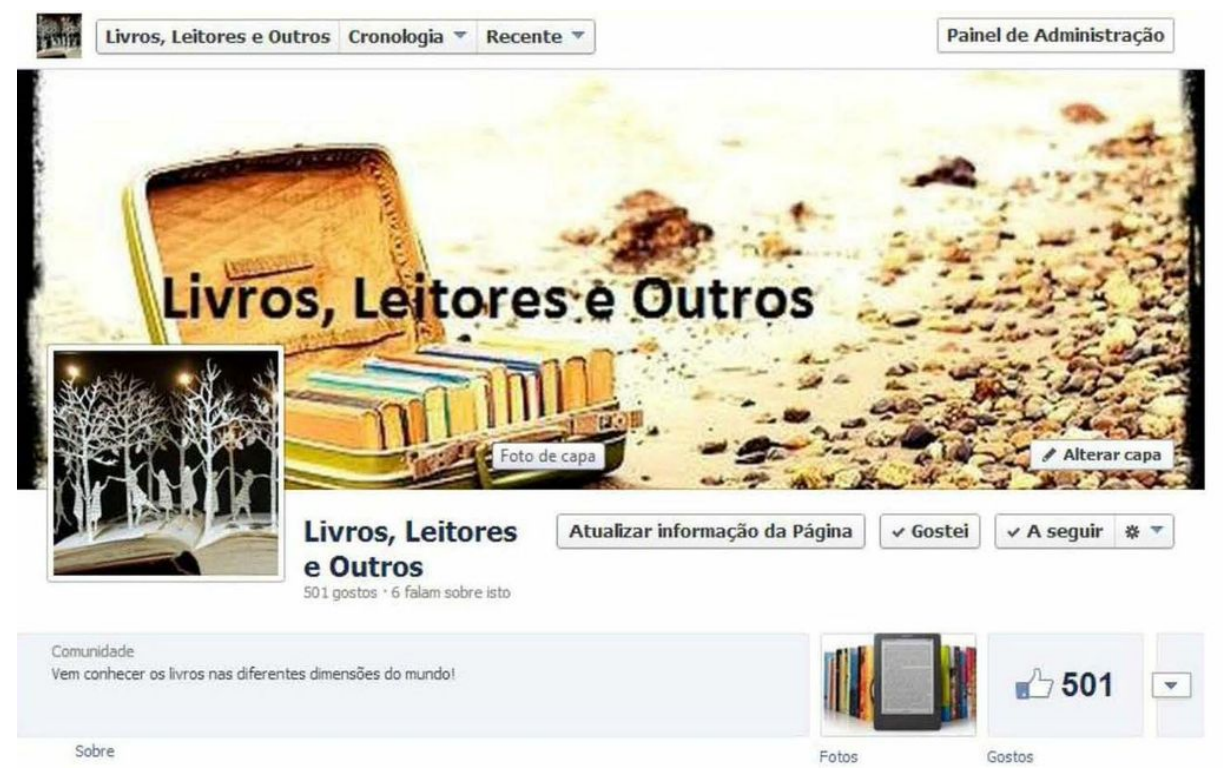

Figura 7 - Conta de Facebook para promoção da leitura e da literatura 


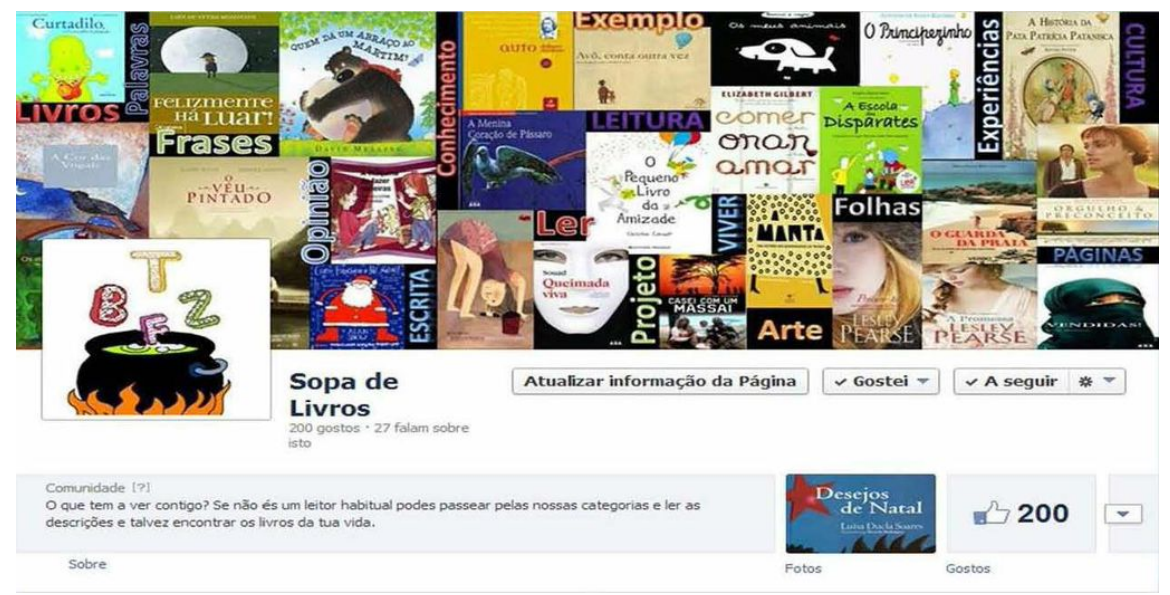

Figura 8 - Conta de Facebook para a promoção da leitura e da literatura

8 - Ler é viver! - Baseado no projeto "Little Free Library" (http://littlefreelibrary.org/), com origem nos EUA, e destinado à partilha livre, gratuita e sem restrições, de livros pela comunidade, a iniciativa Ler é viver! contou também com grande adesão. A iniciativa, realizada nas instalações do Instituto de Educação da Universidade do Minho, durante cerca de dois meses, disponibilizou, para leitura, um conjunto de livros (figura 9). As obras foram colocadas num pequeno espaço (a casinha), sendo facultada a possibilidade de empréstimo, baseado apenas num critério de confiança, sem necessidade de preenchimento de qualquer informação ou de uso de um qualquer cartão de utilizador. 


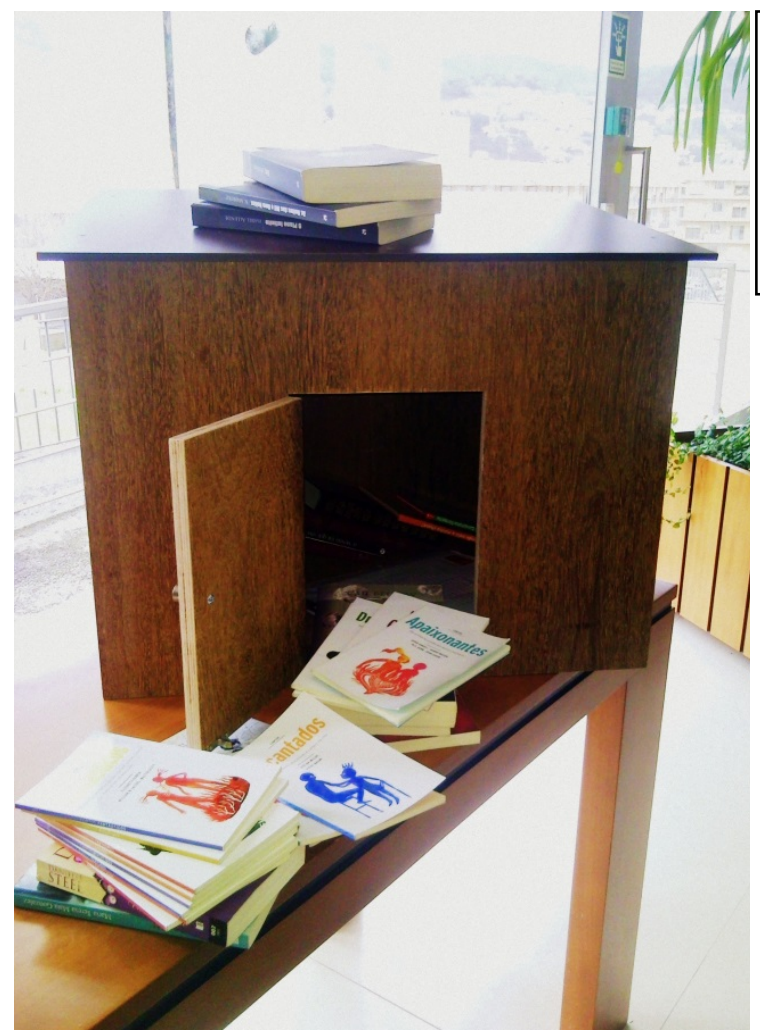

Figura 9 - Pormenor da casinha dos livros, dentro das instalações do Instituto de Educação da Universidade do Minho.

9 - Balneário Literário - é uma atividade desenvolvida junto de público infantojuvenil visando formar leitores em espaços de lazer e de desporto. A atividade decorreu dentro do balneário onde as crianças se equipam antes de treinar, reunindo com elas à volta de quem contava. As crianças, desde cedo, se mostraram alegres e recetivas à informação que o grupo ia partilhando, mostrando-se bastante curiosas e interventivas. As histórias foram contadas em pequenos extratos (os mais relevantes ou significativos), dado que o tempo disponível para a atividade era cerca de 30 minutos, bem antes do treino desportivo. Durante a intervenção, foram sendo colocadas questões ao grupo de crianças sobre os seus hábitos de leitura, obras já conhecidas e seus interesses. Da realização da atividade salienta-se o espírito de cooperação das crianças para com o grupo de voluntários envolvidos na dinamização da atividade e a receção positiva destas à atividade. 
10 - Frases Andantes - consistiu na colocação, nas escadas que dão acesso a um dos pisos do Instituto de Educação da Universidade do Minho, situado no Campus de Gualtar, em Braga (Portugal), de frases motivadoras e inspiradoras que, de algum modo, pudessem estimular a curiosidade pela leitura ou contribuir para a sua promoção. As frases escolhidas foram retiradas de obras como O Pequeno Príncipe, A Ilha do Tesouro ou de obras de Paul Auster bem como de outras de autores comerciais como Paulo Coelho ou Dan Brown.

11 - Chá com Letras - consiste numa atividade de promoção da leitura e da literatura, associando a citações estimuladoras a possibilidade de beber um chá relaxante. Desenvolvida em dezembro, mês que, em Portugal, se carateriza pelo tempo frio, a atividade permitiu encontrar uma pausa na azáfama da vida quotidiana para relaxar, beber um chá quente e ler um pouco de literatura. Os participantes foram convidados a escolher uma pequena caixa, com o formato de um cubo, dentro da qual se encontrava um invólucro com uma tisana e uma citação literária estimuladora, cuja obra seria, posteriormente, facultada havendo interesse da parte do participante (figuras 10, 11 e 12). Escolhida a caixa, chegava o momento de os monitores prepararem o chá quente, servindo-o em elegantes chávenas de porcelana. À medida que bebiam o chá, os participantes podiam, se assim o desejassem, folhear ou ler o livro, do qual tinha sido extraída a citação estimuladora. A experiência, amplamente relatada em Azevedo (2018), permitiu que as pessoas unissem a leitura a um momento de prazer, relaxe, enriquecimento, evolução, envolvimento, paz e conforto.
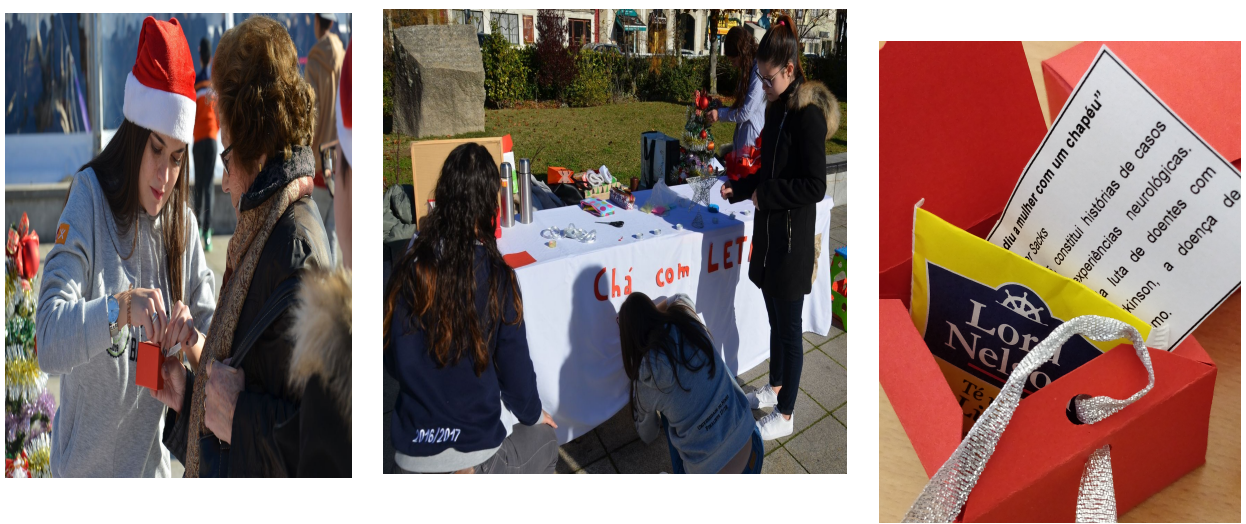
Figuras 10, 11 e 12 - Pormenores da atividade Chá com Letras.

\section{BALANÇO DAS ATIVIDADES}

Estas práticas de promoção da educação literária e da literatura desenvolvidas por alunos finalistas da Licenciatura em Educação Básica da Universidade do Minho demonstraram os seguintes aspetos:

1) Impacto positivo da dinamização dos espaços de leitura em versão digital nas redes sociais, visível na contagem do número de visitantes que explicitam gostar da iniciativa;

2) $\mathrm{O}$ impacto é aprofundado quando, paralelamente à dinamização em ambiente virtual, se complementa com a dinamização em ambiente presencial;

3) A experiência colaborativa permitiu desenvolver uma consciência crítica, nos estudantes universitários, acerca da relevância e necessidade de atividades sistemáticas e intencionais de promoção da educação literária e da literatura junto de públicos diferenciados;

4) Ainda que as atividades tenham tido elevada adesão, com reconhecimento e reiteração das mesmas, por solicitação das entidades que acolheram as iniciativas dos estudantes universitários, não foi possível avaliar o impacto real na consolidação de comunidades leitoras.

5) É de assinalar que o acolhimento institucional e municipal destas iniciativas, através de parcerias, mesmo que informais, contribui para a consolidação destas atividades de promoção da educação literária e da literatura.

Para além do que já enunciámos, temos consciência que a promoção da leitura e a formação de leitores exige a figura de mediadores de leitura qualificados e empenhados, que nem sempre estão presentes nos diversos contextos não formais de leitura. Este será, pois, um caminho a percorrer: não só a formação de novos mediadores de leitura, mas também a conjugação de sinergias entre diversos contextos, na tentativa de que a leitura e a formação de leitores seja cada vez mais um desígnio sentido como comum em toda a sociedade. 


\section{CONCLUSÕES}

O presente artigo apresentou e descreveu bem como realizou o balanço de um conjunto de práticas de promoção da literatura, realizadas em múltiplos contextos não formais da cidade de Braga, Portugal. Estas práticas foram levadas a cabo por alunos da Licenciatura em Educação Básica, no âmbito da unidade curricular de Literacia e Mediação Leitora.

Dada a natureza da intervenção destes alunos em contextos não formais, não nos é possível retirar conclusões taxativas, mas sim avançar com um conjunto de constatações/reflexões. Essas constatações/reflexões possibilitam avançar com alguns indicadores no sentido de considerarmos que os objetivos da intervenção dos alunos foram alcançados.

O número de visitantes dos espaços de leitura em versão digital nas redes sociais permite-nos afirmar que foi possível estimular a leitura e a literatura no ambiente das ferramentas digitais.

As entidades parceiras, onde se implementaram estas práticas, reconheceram a sua importância, possibilitando nos seus espaços a reiteração das mesmas. Constatou-se também que existiu uma elevada adesão a estas práticas por parte do público-alvo a que se pretendia chegar. Neste sentido, certamente podemos afirmar que se promoveu a leitura e a literatura, que se apresentaram ao público-alvo distintos autores e livros e que se fomentou o contacto com diversos espaços/equipamentos como sendo espaços de leitura não formais.

Tendo em conta o tipo de intervenção realizada, não foi possível avaliar o impacto real destas práticas de promoção da literatura na consolidação de comunidades leitoras.

Promover a leitura e a literatura não é apenas tarefa da escola, mas responsabilidade de todos os atores educativos. Se é verdade que a formação de leitores se faz, em larga medida, pelo testemunho e pelo exemplo dado pelos mediadores - ler, gostar de ler, partilhar autores e textos, recomendar, em função de gostos e de interesses cognitivos e outros - , numa geração de nativos digitais (TAPSCOTT, 2009) é relevante que as gerações mais jovens possam 
perscrutar objetos de cultura e interagir com eles, mesmo que eles se apresentem sob roupagens lúdicas. Muitas vezes, bastará uma simples imagem para suscitar a curiosidade intelectual e criar-se a vontade de ler.

Como dissemos noutro lugar (AZEVEDO, 2007), consideramos que é imperioso democratizar o acesso à leitura, suscitando o interesse e o debate acerca dela. Se há espaços habitualmente associados a práticas de leitura pensamos, por exemplo, nas bibliotecas, livrarias ou associações culturais - , outros espaços, eventualmente mais inesperados como associações desportivas, cafés, restaurantes, jardins, lojas ou transportes públicos podem/devem ser percebidos, igualmente, como lugares conaturais ao exercício e à consolidação de comunidades leitoras, na linha, aliás, daquilo que são as linhas de estratégia do Plano Nacional de Leitura português.

A literatura, exibindo o mundo, na paleta das suas multíplices cores, interrogando discretamente o leitor, lidando com valores e com sistemas ideológicos, possui, deste modo, uma importante e não negligenciável dimensão emancipadora e é também a esta luz que a leitura e a conversa acerca dos seus textos é tão pertinente.

De facto, num mundo governado por dissensões e conflitos de vária ordem, a literatura possibilita interrogar as práticas, convidando o leitor a pensar o seu lugar no mundo e a sua relação com os outros. Apresentando-se como um modo de dizer o homem e os seus lugares no mundo, ela permite interpretar, com sentido crítico, não só as identidades, como também as alteridades e é graças a esta sua dimensão ética e, em larga medida, axiológica, em complemento à sua incessante capacidade de revelação de novos rostos, revolucionariamente inovadores relativamente aos padrões de referência que fazem parte do conhecimento que o homem tem do mundo que, desde sempre, a literatura, tal como a arte, tem ocupado um papel tão relevante nas relações de interacionismo sígnico do homem com o seu meio.

\section{REFERENCIAS}

AGUIAR e SILVA, Vítor Manuel. Teoria da Literatura. Coimbra: Almedina, 2007.

AZEVEDO, Fernando (Coord.). Língua Portuguesa e Literatura Infantil. Elementos Nucleares para Professores do Ensino Básico. Lisboa: Lidel, 2006. 
AZEVEDO, Fernando (Org). Formar leitores literários. Ideias e estratégias. Braga: Centro de Investigação em Estudos da Criança / Universidade do Minho, 2018.

AZEVEDO, Fernando e BALÇA, Ângela. (Coord.). Leitura e Educação Literária. Lisboa: Pactor, 2016.

AZEVEDO, Fernando; MARTINS, Jorge. Formar leitores no Ensino Básico: a mais-valia da implementação de um Clube de Leitura. Da Investigação às Práticas: Estudos de Natureza Educacional, v. 1, n.1, p. 24-35, 2011. Disponível em: < https://ojs.eselx.ipl.pt/index.php/invep/article/view/53>. Acesso em: 09 out. 2018.

AZEVEDO, Fernando. Construir e consolidar comunidades leitoras em contextos não escolares. In AZEVEDO, F. (Org.). Formar Leitores. Das Teorias às Práticas Lisboa: Lidel, 2007. p. 149-164.

BAKER, Linda \& WIGFIELD, Allan. Dimensions of Children's Motivation for Reading and Their Relations to Reading Activity and Reading Achievement. Reading Research Quarterly, 34(4), 452-477, 1999. Disponível em: <http://www.jstor.org/stable/748216>. Acesso em: 17 out. 2018.

BALÇA, Ângela \& PIRES, Maria da Natividade Carvalho. Literatura Infantil e Juvenil. Formação de Leitores. Carnaxide: Santillana, 2013.

BALÇA, Ângela; AZEVEDO, Fernando; BARROS, Lúcia. A formação de crianças leitoras: a família como mediadora de leitura, Revista Educação Pública, v. 26, n. 63, p. 713-727, 2017. Disponível em:

<http://periodicoscientificos.ufmt.br/ojs/index.php/educacaopublica/arti cle/view/4382>. Acesso em: 10 out. 2018.

BALÇA, Ângela. A promoção da leitura em contextos não formais. In NICO, B.; NICO, L. P. (Eds). Educações no Alentejo. Mangualde: Edições Pedago, p. 261-264, 2014.

BARROS, Lúcia (coord.). A Leitura como Projeto: Percursos de leitura Literária do Jardim de Infância ao $3^{\circ}$ CEB. Porto: Tropelias \& Companhia, 2014.

BARROS, Lúcia. Educação Literária na Família: Uma Proposta. Tese (Doutoramento em Estudos da Criança) - Instituto de Educação. Universidade do Minho. Braga, p. 705, 2018. 
BOSMA, Bette \& GUTH, Nancy DeVries (Ed.). Children's Literature in an Integrated Curriculum: The Authentic Voice. New York - Newark: Teachers College Press/International Reading Association, 1995.

CERRILlO, Pedro; LARRAÑAGA, Elisa e YUBERO, Santiago. Libros, Lectores y Mediadores. La Formación de los Hábitos Lectores como Proceso de Aprendizaje. Cuenca: Universidad de Castilla-La Mancha, 2002.

CERRILLO, Pedro; SENÍS, Juan. Nuevos tiempos, ¿nuevos lectores? Ocnos, n. 1, p. 19-33, 2005. Disponível em: <http://www.revista.uclm.es/index.php/ocnos/article/view/166/147>. Acesso em: 11 out. 2018.

CERRILLO, Pedro. Literatura infantil e mediação leitora. In AZEVEDO, F. (Org.). Língua Materna e Literatura Infantil. Elementos Nucleares para Professores do Ensino Básico. Lisboa: Lidel, 2006. p. 33-46.

CERRILLO, Pedro. Literatura Infantil y Juvenil y Educación Literaria. Hacía una nueva enseñanza de la literatura. Barcelona: Octaedro, 2007.

CERRILLO, Pedro. Sociedad y Lectura. La importancia de los mediadores en lectura. In RAMOS, A. M. (Org.). Formar Leitores para Ler o Mundo. Lisboa: Fundação Calouste Gulbenkian, 2010. p. 95-104.

Cullinan, Bernice E. La Lectura en el Aula: Ideas y Estrategias de Enseñanza para la Formación de Lectores. México: Trillas, 2003.

ECO, Umberto. Lector in fabula: la cooperazione interpretativa nei testi narrativi. Milano: Bompiani, 1983.

MATA, Lurdes. A descoberta da Escrita: Textos de apoio para Educadores de Infância. Lisboa: Ministério da Educação, 2008.

MCMAHON, Susan; RAPHAEL, Taffy. The Book Club Connection: Literacy Learning and Classroom Talk. New York: Teachers College Press, 1997.

MENDOZA, António. Función de la literatura infantil y juvenil en la formación de la competencia literaria. In CERRILLO, Pedro; GARCÍA, Jaime (Coords.), Literatura Infantil y su didáctica. Cuenca: Ediciones de la Universidad de Castilla-La Mancha, 1999. p. 11-54. 
MONTEIRO, Ofélia Paiva. Ofélia Paiva Monteiro em entrevista - «A Literatura é um elemento perturbador», Prelo, 2016. Disponível em: $<$ http://prelo.incm.pt/2016/11/ofelia-paiva-monteiro-ementrevista.html?m=1>. Acesso em: 11 out. 2018

PNL. Plano Nacional de Leitura. 2018. Disponível em: <http://www.pn12027.gov.pt/np4/home>. Acesso em: 10 out. 2018

POSLANIEC, Christian. Donner le Goût de Lire. Des Animations pour faire Découvir aux Jeunes le Plaisir de la Lecture. Paris: Editions de la Martinière, 2004 .

RAPHAEL, Taffy; PARDO, Laura; HIGHFIELD, Kathy. Book club: a literature-based curriculum. Lawrence, Mass.: Small Planet Communications, 2002.

RIBEIRO, Iolanda e VIANA, Fernanda Leopoldina (Org.). Dos Leitores que temos aos leitores que queremos. Ideias e Projetos para promover a leitura. Coimbra: Almedina, 2009.

SORENSEN, Marilou R. \& LEHMAN, Barbara A. (Ed.). Teaching with Children's Books. Paths to Literature-Based Curriculum. Urbana: National Council of Teachers of English, 1995.

TAPSCOTT, Don. Grow up digital. How the net generation is changing your world. New York - Chicago - San Francisco: McGrawHill, 2009.

Recebido em 12/10/2018 Aprovado em 28/11/2018 